\title{
The Life Course Consequences of Single-Sex and Co-educational Schooling
}

Alice Sullivan and Heather Joshi

Acknowledgements: This work was funded by ESRC Award RES-000-22-1085. Thanks are due to the National Child Development Study survey members for their contribution over many years. We would also like to thank our late colleague, Professor Diana Leonard (1941 2010), who was PI of the project.

Keywords: Single-sex; co-educational; school; gender

\begin{abstract}
This chapter reports on a study examining whether attending single-sex rather than coeducational secondary schools made a difference to the lives of a cohort of men and women born in Britain in 1958. The project aimed to assess the impact of single-sex secondary schooling, not just on short term and narrowly academic outcomes, but also on longer term social, psychological and economic outcomes. In a generally gendered environment for adults, did it make any difference to have been to a gender segregated school, and in what way? This chapter provides an overview of our findings, and a discussion of the implications for policy and for future research.
\end{abstract}




\section{Background}

Controversies about co-education at secondary schools in Britain began at the end of the nineteenth century and continue to the present. However, the arguments for and against coeducation have changed over time, with changing gender differences in educational aspirations and attainment, while the number of the single-sex schools has declined steadily. The evidence regarding single-sex schools must therefore be placed in historical context.

Traditionally, single-sex secondary schooling was the norm. However, in the 1920s, "progressives" began to argue that co-education could help overcome "sex antagonisms," improve the quality of marriage and help prevent homosexuality (Brice, 1980; Dyhouse, 1985; Faraday, 1989). In the 1960s and 70s, Dale $(1969,1971,1974)$ reported that boys, girls and especially teachers were happier in co-educational secondary schools, where boys did better academically. Benn and Simon (1970) used this in support of comprehensive schooling, which they believed should be a common school for all children. Others in the same period continued to support single-sex schools for religious reasons and/or to control (mainly girls') sexual behavior — to guard against early sexual relationships and premarital pregnancy.

In the 1970s and 80s, feminists reasserted that single-sex schools were better for girls, even if co-education might be better for boys (Spender \& Sarah, 1980). Girls were said to get more attention from teachers and a fairer share of resources when boys were not present; and the heads of girls' schools suggested their schools encouraged girls' ambitions (Shaw, 1976). This was countered by arguments that it was the school sector (private, grammar or comprehensive) that mattered most (Bone, 1983). If it seemed that girls did better if they went to single-sex schools, this was because single-sex schools were likely to be longer established, academically selective and recruited from higher socio-economic groups. 
Today the concern is more narrowly with GCSE examination results and which type of school (or type of grouping within mixed schools) produces the best performances (Smithers \& Robinson, 2006; Spielhofer, Benton, \& Schagen, 2004). Single-sex classes are being tried in mixed schools in the hope of raising boys' performance in particular (Warrington \& Younger, 2001; Younger \& Warrington, 2006), reflecting increasing concerns about boys’ "underachievement" in school.

Deeply held opinions on single-sex and co-educational schooling continue and there is a lack of rigorous research evidence. Most available data is based on small scale, synchronous studies, or is anecdotal. The project we report on here aimed to make a long overdue assessment of the short- and long-term effects of single- and mixed-sex schooling using evidence from a large and nationally representative longitudinal study. This has followed individuals from birth, through the education system and into adulthood. We have been able to control for crucial confounding variables (such as prior academic attainment and social class) and to provide information on the longer term impacts of schooling, which have never previously been tested. We have reported the results of this study in various places (Leonard, Joshi, \& Sullivan, 2007; Sullivan, 2009; Sullivan, Joshi, \& Leonard, 2010, 2011, 2012). The purpose of the current chapter is to provide an overview of our findings regarding the effects of single-sex schooling in different life-domains. This evidence adds to our understanding of the way in which school contexts can influence gendered aspirations and attainment.

\section{Research Questions}

Arguments in favor of and against single-sex schooling have been put forward from a range of different perspectives, with some feminists on either side of the debate. Hypotheses 
emerging from the views of commentators are varied and conflicting. Single-sex schooling will improve the academic attainments of girls or of boys or both, or will be detrimental to both sexes. Single-sex schooling will produce confident and successful women, or women who cannot compete with men. It will lead to difficult relationships between the sexes, or to more equal relationships (Leonard, 1996).

Before addressing the potential consequences of attending a single-sex school, it was crucial to examine the issue of the ways in which boys and girls attending single-sex schools differed from their peers at coeducational schools, particularly in terms of key characteristics such as family background and cognitive test scores. We went on to examine outcomes from age 16 to age 42, and our findings can be divided into 4 main areas:

- During schooling we focused on happiness/wellbeing at school, truancy and academic self-evaluation.

- Academic attainment was measured at ages 16, 18 and 33: We examined attainment in secondary school examinations and later degree success, and the gender segregation of subjects studied.

- We examined occupational outcomes in mid-life (age 42), namely labor market participation, occupational status, wages, and occupational gender segregation.

- Also in mid-life, we looked at social outcomes such as attitudes to gender roles, marriage, and the domestic division of labor.

In each case the experience of men and women is compared, and we assess whether outcomes are linked to single-sex and co-educational schooling once potential confounding variables have been controlled. 


\section{Data and Methods}

The National Child Development Study (NCDS) is a longitudinal study of a single cohort born in Britain (i.e. England, Scotland and Wales, but not Northern Ireland) in one week in 1958 (Power \& Elliott, 2006). NCDS is a continuing, multi-disciplinary longitudinal study, with data relating to health, education, wellbeing, family formation and labor market participation, among other things. The cohort members have been followed up throughout their lives, and were last surveyed for the ninth time in 2008, when they were 50 years old. The initial sample was designed to be nationally representative of all children in Britain, and achieved a sample size of 17,414 (Bynner \& Joshi, 2007). By the third follow up, when the children were aged 16, 14,761 remained in the study. Hawkes and Plewis' (2006) examination of attrition and non-response in the NCDS finds systematic yet modest predictability in attrition, wave non-response, and missing education data, thus supporting the assumption of ignorable non-response. Neither parental education nor social class were significant predictors of non-response. The distribution of educational qualifications gained by the cohort members by age 33 was closely in line with other data sources (Dale \& Egerton, 1997).

Previous studies of the effects of single-sex schooling have been criticized for inadequate controls for prior attainment and family background. Given the concentration of single-sex schools in the private and selective sectors, it is important to control for such potential sources of bias. The NCDS gives exceptionally rich information on various aspects of the respondents, their schools and their parents, allowing crucial confounding variables to be controlled. The parents were interviewed at the childhood data collections, providing information on social background, parents' education, and other characteristics. 
Data were also collected directly from the children through tests and questionnaires administered at school at the ages of 7,11 and 16. Extensive information on academic examination results was collected directly from the schools. From the age of 16 onwards, the respondents themselves were interviewed.

The NCDS cohort took a range of cognitive tests at ages 7 and 11, allowing us to control for prior attainment in an unusually fine-grained way (Steedman, 1980, 1983b, $1983 c)$

The sample is not clustered, i.e. pupils are not sampled within schools. The sample consists of all children born in Britain in the relevant week. Many schools would be represented by a single cohort member. It is therefore neither possible nor necessary to apply a multilevel statistical model to these data. A further limitation is that, due to the small numbers of ethnic minority individuals included in the NCDS, it is not possible to conduct analyses according to ethnic group. 98\% of the NCDS sample were white (at the 1969 survey).

\section{Results}

\section{Who attended single-sex schools in 1974 ?}

The NCDS cohort experienced a state secondary education system that was in transition from the tripartite to the comprehensive system. Under the tripartite system, children sat an exam around age 11 (called "the eleven-plus") which determined whether, in the September following their $11^{\text {th }}$ birthday, they would attend an academically selective Grammar or Technical school, or a Secondary Modern school, designed for the majority of pupils. Comprehensive schools were intended to replace this selective system with all-ability schools. 
$58 \%$ of the NCDS respondents attended Comprehensive schools, but $11 \%$ still attended Grammar and Technical schools, 22\% attended Secondary Modern schools, and 6\% attended Private and Direct Grant schools. Private schools are fee-paying schools. Direct Grant schools were fee-paying, but had a proportion of state-funded places. Henceforth, we refer to Grammar and Technical schools as "Grammar schools," and Private and Direct Grant schools as "Private schools." Taking the NCDS sample as a whole, $24 \%$ of boys and $27 \%$ of girls aged 16 attended single-sex schools. However, there was great variation between school sectors. Within the private sector, single-sex schooling was the norm, with $78 \%$ of private school pupils attending single-sex schools. In the state sector, however, $67 \%$ of grammar school pupils against $26 \%$ of secondary modern and $11 \%$ of comprehensive school pupils went to single-sex schools. There were also more boys than girls at mixed schools in the private, secondary modern, comprehensive and special sectors. The latter catered for a small number of pupils with special needs, and these are excluded from all subsequent analyses. More boys than girls attended such schools, and there were especially few girls at single-sex special schools.

There was also substantial regional variation in the extent of provision of single-sex schooling in 1974. Single-sex schooling was most common in London and the South East, with $49 \%$ of pupils ( $51 \%$ of girls and $46 \%$ of boys) attending single-sex schools. These were common throughout the state sector, even among comprehensives. Single-sex schooling was least common in Scotland, catering for only $6 \%$ of girls and $7 \%$ of boys in the study.

We modeled attendance at a single-sex school in order to identify which children were more likely to go to one. The results of separate binary regression analyses for boys and girls are reported in Table 16.1. Single-sex schools were more academically and socially selective than co-educational schools, reflecting their being more prevalent in the private and grammar sectors. Within each school sector, only modest differences in who attended singlesex versus co-educational schools were found, which is reassuring in terms of dealing with 
selection bias. School sector attended (i.e. private, comprehensive, secondary modern or grammar) and region were the key predictors of individuals experiencing single-sex

schooling. The effect of social class was fully captured by the school sector variable. For boys, but not for girls, test scores at age 11 were significantly positively linked to attending a single-sex school. For both sexes, there was an interaction between test scores at age 11 and private schooling, in line with the greater academic selectivity of single-sex schools within the private sector.

In summary, comprehensive schools were generally less likely to be single-sex than the other types of school, but within each school sector, children who attended single-sex and coeducational schools were similar.

Table 16.1 Here

2. Did single-sex schooling have any impact on: liking school, behavior and wellbeing during adolescence?

Our second set of research questions related to the points stressed by Benn and Simon (1970) and Dale $(1969,1971,1974)$ concerning the supposed greater happiness and wellbeing of boys and girls in mixed-sex schools, as well as their supposed better behavior

Whether pupils liked school 
At age 16, the NCDS cohort members were asked to respond to the statement "I do not like school." Figure 16.1 shows a breakdown of responses to this statement according to the pupil's sex and whether they attended a single-sex or co-educational school.

\section{Figure 16.1 Here}

Figure 16.1 appears to show that pupils were happier in single-sex schools. However, this is misleading because pupils in private and grammar schools were generally more likely to say that they liked school. Figure 2 below shows the proportions of pupils responding "usually untrue" or "not true at all" to the statement "I do not like school" (i.e. those who generally liked school) by type of school.

\section{Figure 16.2 Here}

Pupils at private and grammar schools were most likely to say that they liked school, and pupils at comprehensives were slightly less likely to like school than pupils at secondary moderns. Girls liked school more than boys at comprehensives, but this was not true at private and grammar schools.

Within each school sector, there was therefore a slight tendency for both boys and girls at co-ed schools to be more positive about school than those in single-sex schools. This is in line with Dale's findings from his various surveys of grammar and former grammar school pupils. However, we found the differences to be slight in each sector and we did not find that girls were "decidedly happier" in mixed schools (cf. Dale, 1971). 
Binary logistic regression analysis (reported in Sullivan et al., 2012) showed that, conditioning on background controls, the link between liking school and being at a single-sex school was statistically significant for boys, but not for girls. In addition, school sector showed statistically significant differences for boys (positive private, grammar and secondary modern parameters) but not for girls.

Truancy at age 16

Pupils were asked whether they had truanted at all during the last year. Both boys and girls were less likely to report truanting from private and grammar schools. Single-sex schooling was also significantly associated with a lower likelihood of reported truanting, conditioning on school sector and other background controls. These findings are based on a binary logistic regression analysis reported in Sullivan et al. (2012).

Psycho-social adjustment at age 16

Both mothers and teachers reported on the child's behavioral adjustment using the Rutter aggression and anxiety scales (Rutter, Tizard, \& Whitmore, 1970). We have used the mother's report since the teacher's report may be conditioned by the school context. We found no impact of single-sex schooling on scores for either anxiety or aggression, based on regression analysis reported in Sullivan et al. (2012).

In summary, for boys, single-sex schooling was linked to a dislike of school. It is intriguing that school sector was linked to the chances of liking school for boys but not for girls, with boys 
being less happy at comprehensive schools. Although we can only offer tentative explanations for this finding, it does point to the possibility that ostensibly the same school structures and practices can be experienced differently by boys and girls. Research which fails to analyze outcomes for girls and boys separately will not pick up on the intersection of gender and school structures in producing outcomes, whether these are purely academic or wider. It is also notable that a great deal of research was carried out on the question of the effects of comprehensivisation on academic outcomes, but, as far as we are aware, little attention has been given to the question of pupils' enjoyment within the different school sectors.

We found that both sexes were less likely to truant from single-sex schools. It is possible that pupils truanted from school as a direct consequence of the presence of the opposite sex. However, this may be more likely to reflect the different cultural and disciplinary regimes prevailing within single-sex and co-educational schools at the time. It is possible that this also in turn accounts for boys' greater dislike of single-sex schools.

\section{Was single-sex schooling linked to academic self-concept in different subject areas?}

The cohort members were asked to rate their own academic abilities in a range of academic subjects. Figure 16.3 shows boys' and girls' evaluations of their own abilities in math, English and science. Boys rated themselves more highly in math and science, while girls rated themselves more highly in English. $21 \%$ of girls and $10 \%$ of boys stated that they had never studied science.

\section{Insert Figure 16.3}


These gender gaps in self-concept were moderated by single-sex schooling. In regression analyses conditioning on background controls (Sullivan, 2009), including verbal and non-verbal test scores at ages 7 and 11, we found that girls at single-sex schools were less likely than co-educated girls to see themselves as below average in math and science, and less likely to see themselves as above average in English. Boys at single-sex schools were more likely than co-educated boys to see themselves as above average in English. This confirms feminist arguments of the 1970s: gender stereotypes are exacerbated in mixed schools. The gender gap in self-confidence is smaller in the single-sex sector. These analyses were also replicated for the 1970 British Cohort Study (BCS70) (Sullivan, 2006).

To the extent that single-sex schooling affected academic self-concept, it generally promoted the gender-atypical. Conversely, co-educational schooling reinforced gendered selfconcepts among pupils.

\section{Did boys and/or girls get better overall academic results in single-sex schools?}

This is the one area in which the cohort studies have previously been used to look at differences between single sex and co-educational schooling, although Steedman's (1983a) analyses were limited to exam results at age 16. Our analysis of academic attainment at $\mathrm{O}$ (Ordinary) level at age 16 and A- (Advanced) level at age 18 is limited to schools in England and Wales, since Scotland has different qualifications.

National public examination passes at age 16 
In Britain, pupils sat public examinations at age 16, the legal school-leaving age for this cohort. Separate exams were set for different subjects, and the most able students would have sat exams in around eight subjects. There were two sets of public examinations: O levels were intended for the most academically able, and CSEs (Certificate of Secondary Education), for the less able. O level grades ranged from A-G, with A-C grades being treated here as a pass. A top grade CSE (grade 1) was deemed equivalent to a grade $\mathrm{C}$ at $\mathrm{O}$ level. Here we examine the chance of getting 5 or more passes at O level A-C or CSE1. This was the typical benchmark for progression to further academic track education, for which grades D and E in O level, while technically not failures, were not seen as adequate.

The raw figures suggest an enormous advantage for single-sex schools in examination attainment at 16 in $1974.15 \%$ of co-ed boys achieved 5 or more passes, compared to $37 \%$ of single-sex boys. For girls, the gap was even wider: $14 \%$ of co-educated girls achieved 5 or more passes, compared to $42 \%$ of single-sex educated girls.

However, these raw differences are extremely misleading, given the concentration of single-sex schools within the private and selective sectors. Once school sector is taken into account, the difference in exam results between single-sex and co-educational schools appears generally more modest (Figure 16.4).

\section{Figure 16.4 Here}

The results of a binary logistic regression analysis controlling for a relevant background controls are reported in Sullivan et. al. (2010). This analysis shows an advantage for girls at single-sex schools, but no statistically significant effect of single-sex schooling for boys.

National public examination subject passes at age 16 
We examined whether single-sex schooling was associated with the likelihood of gaining passes in specific subject disciplines. In general, a higher proportion of girls achieved passes in English and modern languages, while a higher proportion of boys achieved passes in math, physics and chemistry.

Figure 16.5 shows the number of exam passes in math, physics and chemistry gained by the subset of boys and girls at co-ed and single-sex schools who gained at least one pass at Olevel/CSE1, Girls at girls' schools were more likely to get O-levels in all 3 subjects, and less likely to get O-levels in none of them. Boys at boys' schools were no more likely than co-ed boys to get three passes, but were more likely to get one pass, and correspondingly less likely to get none.

\section{Figure 16.5 Here}

Figure 16.5 also shows the number of passes in English, French, and an additional modern language gained by boys and girls at co-ed and single-sex schools. Boys at boys' schools were more likely than co-educated boys to get 2 or 3 passes in these subjects, while girls at singlesex schools were more likely to get two passes, but no more likely to get 3 .

We modeled these outcomes using a partial proportional odds model (Sullivan et al., 2010). Once appropriate controls were included in the model, we found a positive girls' school effect and a negative boys' school effect on the number of passes gained in math, physics and chemistry. We also found positive differentials of single-sex schooling for English and modern languages for both boys and girls. Overall, the results confirm that girls did better in math and science, and boys did better in languages, at single sex schools. That is to say, co-education was associated with increased gender differentiation. 


\section{Curriculum studied}

The information we have about the curriculum available to the cohort members is limited, but at age 16 they were asked to report on whether they had "ever studied" a range of subjects: math, science, English, art, music, practical subjects and sports.

We found that, conditioning on background controls (Sullivan, 2009), girls were more likely to report never having studied math and science, but single-sex schooling made no difference to their chance of ever studying these subjects. Girls at single-sex schools were more likely than girls at mixed schools to have studied art and music, suggesting that girls' schools sought to cater to girls' perceived interests, rather than trying to provide access to a gender atypical curriculum. In contrast, boys at single-sex schools were more likely never to have studied practical subjects and sports.

Examination attainment at 18

A minority of students stayed on at school from 16 to 18, and studied for "A" (Advanced) level exams. $14.6 \%$ of boys and $14.3 \%$ of girls gained one or more A-level passes (at grades A to E) by 1976. Binary logistic regression analyses (Sullivan et al., 2010) revealed no statistically significant difference in the likelihood of gaining one or more A-level passes (at grades A to E) at a single-sex or co-educational school, for either boys or girls. However, there were substantial differences in the subjects that boys and girls passed at A-level at single-sex and coeducational schools. 
Figure 16.6 shows that girls at single-sex schools were more likely than co-educated girls to get at least one A-level in math, physics or chemistry. Boys at single-sex schools were slightly less likely than co-educated boys to get any A-levels in these subjects. Girls at both co-educational and girls' schools had similar chances of getting an A-level in English or a modern language. Boys at boys' schools were more likely than co-ed boys to get an A-level in these subjects.

\section{Figure 16.6}

The pattern shown in these tables is confirmed by logistic regression analyses reported by Sullivan et al. (2010). Boys were significantly more likely to get an A-level in English or a modern language if they went to a boys-only school. Girls were significantly more likely, and boys significantly less likely, to get an A-level in math, physics or chemistry if they attended a single-sex school.

In summary, girls at single-sex schools were substantially more likely than their co-educated peers to achieve a high level of examination success at age 16 , but boys were neither significantly advantaged nor disadvantaged in terms of overall examination attainment by attending single-sex schools. One interpretation of this would be that boys tend to be relatively disruptive in class, and therefore girls receive less attention from teachers when there are boys present. Single-sex schools were associated with attainment in gender atypical subject areas for both boys and girls. This supports the view that co-educational schools tended to exacerbate the problems of sex-stereotyping rather than remedy them. This may be due to peer pressures in the presence of the opposite sex. 


\section{Was there an impact of single-sex schooling on post-school qualifications?}

Here we use the national sample again, including Scotland.

Qualifications gained by age 33

Cohort members were asked about any new qualifications they had gained at each wave of the survey. Single-sex schooling was not significantly associated with either the chance of getting a degree by the age of 33, or having no qualifications by then, once school sector had been controlled (Sullivan et al., 2010)

Subject of qualifications gained by age 33

The subject area of the highest qualification gained (reported by the cohort member) was significantly related to single-sex schooling. Because the cell sizes for each individual subject area were small, we grouped subjects according to whether they were "male-dominated," "female-dominated" or "integrated," "integrated disciplines" being defined as those with no more than $60 \%$ of one sex (coding due to Dale \& Egerton, 1997). Figure 16.7 shows that women who had attended girls' schools were more likely than co-educated women to have "male-typed" highest qualifications; and men who went to boys' schools were more likely than co-educated men to have "female-typed" qualifications.

\section{Figure 16.7 Here}


Regression analyses (Sullivan et al., 2010) confirmed that, other things equal, girls were significantly more likely to study "male-dominated" subjects, and less likely to study "femaledominated" subjects if they had attended single-sex schools.

So, having been to a single-sex school was not linked, except through selective schooling, to the chances of an individual getting a degree or other post-school qualification, but it did influence the subject area of that qualification.

In summary, single-sex schooling was not linked to the level of qualification achieved by age 33, but was linked to the subject area of the qualification, suggesting long-term consequences of the stronger sex-stereotyping of the subject options taken by boys and girls in co-educational schools.

\section{Did single-sex schooling have any impact on aspects of personal wellbeing in adult life?}

To assess mental health and general wellbeing, we looked at the responses given at age 42 to the "malaise inventory," a 24-item scale designed to assess tendency to depression (Rutter et al., 1970). The items in this scale range from relatively minor symptoms, e.g. "Do you often have bad headaches?", to severe problems, e.g. "Have you ever had a nervous breakdown?"

Linear regression analysis (Sullivan et al., 2012) showed that, conditioning on background controls, there was a significant interaction between school sector and single-sex schooling. Men who had attended single-sex boys' schools in the private and grammar sectors suffered from slight but statistically significantly higher levels of malaise compared to their peers from comprehensive schools. 
In summary, it is interesting that men who had attended selective and private single-sex schools were at greater risk of depression than men who had attended comprehensive single-sex schools. However, more important from our point of view is the absence of any overall difference for either men or women in their depression risk according to whether they attended a single-sex or co-educational school.

\section{Did single-sex schooling have any impact on adult domestic life and views on gender equality?}

Marriage

In the 1958 cohort, the vast majority of those who formed any partnership eventually married. We found no link between single-sex schooling and the chances of marriage by the ages of 33 or 42.

We looked for evidence of same-sex relationships in household composition, but such cases were far too rare - only 21 men and 22 women reported living with same-sex partners at age 42 - to be a reliable indicator of sexual preference, let alone a basis for analysis. We are therefore unable to comment on whether co-education did provide the "clean, healthy natural atmosphere" so commended by its early advocates (see Dyhouse, 1985 on the Progressive Education Movement).

Partnership quality at 42 
Cohort members who were married or cohabiting were asked to rate the quality of their relationship from 1 (extremely happy) to 7 (extremely unhappy). They were also asked whether they ever regretted marrying or cohabiting with their partner, and whether they would marry/cohabit with the same person if they could have their time again. We modeled this outcome using binary logistic regression (modeling "extremely happy" in contrast to any other response) and found that the coefficient for single sex schooling was negative for both sexes, but not statistically significant for men. For women, it just achieved statistical significance at the 0.05 level (Sullivan et al., 2012).

\section{Divorce}

In addition, we examined the risk of divorce or separation by age 42 for those who had ever been married. Men who had been to single-sex schools were somewhat more likely to have divorced or separated (except in the private sector) than those in co-educational schools (see Figure 16.8).

\section{Figure 16.8 Here}

Regression analyses (Leonard et al., 2007; Sullivan \& Joshi, 2012) conditioning on background controls show that there was a statistically significant increased risk of divorce or separation for men from single-sex schools. For women, however, there was no significant link.

Division of labor in the home and attitudes to women's employment 
At age 33, cohort members who were married or cohabiting were asked whether they or their partner most often carried out a range of household tasks: cooking the main meal, laundry, cleaning, shopping, etc. We found no significant link between single-sex schooling and later domestic division of labor.

At age 33, cohort members also responded to a series of Likert questions regarding their attitudes towards gender and work, such as "there should be more women bosses," "men and women should do the same jobs," "where both partners work full-time, housework should be shared equally," etc. We again found no link between single-sex schooling and attitudes to gender roles on these measures.

\section{Childbearing}

Regression analyses on outcomes for men and women show no link between single-sex schooling and either the chance of having a child by age 42 , or age of first childbearing. In particular, despite the concerns of religious opponents of mixed schooling for adolescents, we found no significant deterrent effect of single-sex schooling on teenage parenthood for either girls or boys.

Overall, there were a large number of outcomes for which we could show no effect of attending a single-sex school. Perhaps surprisingly, teenage pregnancy was no more or less likely for respondents from single-sex schools. There was no difference in the likelihood of having children, or in the age of first childbirth, according to whether the respondent had been to a single-sex or a co educational school. Neither attitudes to working women, nor the domestic division of labor, were linked to attendance at a single-sex school, for either men or women. There was little link between single-sex schooling and reported relationship quality for either 
sex (there was a marginally significant dip in quality for women who had been to girls'

schools). However, for men, there was a statistically significant link between single-sex schooling and divorce. This lends some support to those who have expressed concerns about the impact of single-sex schooling on later relationships between the sexes, though it is unclear why this impact on divorce should be limited to men.

\section{Was single-sex schooling associated with any labor-market outcomes at age 42 (Year} 2000)?

Women's labor market participation and whether they were working, and, whether jobs were full or part-time is shown in Table 16.2. $45 \%$ of women born in 1958 were in full-time employment at age $42,34 \%$ were in part-time employment, and $13 \%$ were at home looking after their families. (88\% of men were in full-time work.)

\section{Table 16.2 Here}

We modeled women's likelihood of being in (i) full-time employment, (ii) part-time employment and (iii) being at home with the family (Sullivan et al., 2011). Conditioning on relevant background controls, single-sex schooling was not significantly associated with any of these outcomes.

Socio-economic status at age 42 
Socio-economic status is based on the individual's current or most recent job at age 42 , categorized according to the National Statistics Socio-economic Classification (NS-SEC). NSSEC is an occupational schema, and determines class position in terms of employment relations (Goldthorpe \& McKnight, 2006). Figure 16.9 shows the socio-economic class of the cohort members' current or most recent occupation at age 42 . Women were under-represented among employers, managers and professionals, as well as skilled manual and own-account workers. Women were over-represented among junior non-manual and personal service workers and ancillary professionals (this category includes teachers and nurses).

\title{
Figure 16.9 Here
}

\begin{abstract}
Although the NS-SEC occupational classification cannot be viewed as a straightforward hierarchy, the first three categories, comprising employers, managers and professionals, are generally seen as relatively high status, and often referred to as the "service class" or "salariat." We modeled entry to the salariat by age 42 in order to assess whether single-sex schooling was linked to this outcome, conditioning on controls for prior characteristics (Sullivan et al., 2011). We found no significant link between single-sex schooling and access to the salariat for either men or women.
\end{abstract}

Gender segregation of occupations

Many occupations are highly sex-segregated. We used the classification of occupational segregation proposed by Hakim (1998), where occupations with $25 \%$ to $54 \%$ women are described as "integrated." The asymmetry, that $25 \%$ women is considered integrated, but $25 \%$ men is considered women-dominated, is designed to reflect the fact that there were 
fewer women than men in the labor market. This definition is not necessarily suitable for all times or places. Figure 16.10 shows the proportions of men and women from single-sex and co-educational schools who were in women-dominated, men-dominated or integrated jobs at age 42 .

\section{Figure 16.10 Here}

Figure 16.10 gives the impression that men and women who went to single-sex schools went on to have a less sex-segregated experience of the labor market, since single-sex educated men and women were relatively likely to be found in "integrated" occupations. However, the integrated occupations also tended to be higher status than the sex-segregated occupations. Thus, the fact that the single-sex schools were found disproportionately in the private and grammar sectors largely accounts for the apparent effect of single-sex schooling.

In regressions controlling for pupils' background characteristics (Sullivan et al., 2011), no significant effect of single-sex schooling on occupational segregation at age 42 was found. We modeled the likelihood of the cohort members being in: (i) integrated, (ii) male dominated, and (iii) female dominated occupations, using logistic regression, and ran separate regressions for men and women.

Wages at age 42

Figure 16.11 shows the mean hourly wages of men and women in paid employment (reported by the cohort members), according to whether they had attended single-sex or co-educational schools, and according to school sector. Women were paid substantially less than men; but across school sectors, women who had attended single-sex schools gained higher wages. 


\section{Figure 16.11 Here}

Regression analyses (Sullivan et al., 2011) confirm that, conditioning on background controls, there was a statistically significant positive association between single-sex schooling and wages for women, but not for men. Women who had been to girls' schools received a pay premium of about $5 \%$ at age 42 compared to other women. This advantage was accounted for by their superior examination results at age 16. It may seem surprising that single-sex schooling should have had a positive impact on women's wages, despite having no statistically significant impact on access to the salariat or to integrated or male-dominated occupations. It is likely that these variables are too broad to pick up the effect identified by the more fine-grained wages variable.

Our analyses also established that men gained more advantage than women from having attended private schools and from having fathers with higher social class jobs. This implies that the study of social mobility needs to take account of gendered processes.

Overall, while the men and women of the 1958 cohort had different experiences of paid work and its remuneration at age 42 , we found little evidence that having attended a single-sex secondary school had a direct impact on labor market success, or occupational segregation. For men, we found a lasting advantage from having attended a private school, but nothing directly attributable to having been educated with or without girls. Among girls, we did find a long-term legacy of having been to a single-sex rather than a co-educational school. Women who had been to girls' schools received a pay premium of about $5 \%$ at age 42 compared to other women. This advantage was accounted for by their superior examination results at age 16 . 


\section{Summary and Conclusion}

Twice as many graduates in the 1958 cohort had been to single sex schools as the rest of the cohort (46\% versus $22 \%$ ). This tells us that a co-educational background is less common for the currently middle-aged elite than for most of their contemporaries. However, this reflects the socially selective nature of the single-sex schools, rather than their single-sexness in itself. This confirms the importance of controlling adequately for selection bias, something which previous studies of single-sex education have rarely been able to do.

We found that single-sex schooling had a positive impact on academic outcomes at age 16 for girls, and no impact at all for boys. Single-sex schooling was not independently linked to the likelihood of gaining A-level or degree level qualifications.

However, we did find that single-sex schooling was in itself related to girls getting qualifications in math and sciences and boys getting qualifications in English and modern languages. Also, girls at girls' schools were more confident than co-educated girls in their abilities in math and sciences, while boys at boys' schools were relatively confident in their abilities in English. So, single-sex schooling moderated the effect of gender-stereotyping in terms of self-concept and choice of field-of-study.

For boys, single-sex schooling was also linked to a dislike of school, and a greater chance of divorce by age 42 . For girls, the picture was more positive, as single-sex schooling was linked to higher wages by 42 . For both sexes, a wide range of outcomes were not related to single-sex schooling. Perhaps most surprisingly, there was no link to attitudes towards gender roles.

It is generally positive research findings which generate the most interest. However, it is important not to lose sight of the fact that most of our results showed no significant difference between people who had attended single-sex and co-educational schools. Overall, then, we can 
conclude that single-sex schooling had less impact on many of the outcomes considered here than might have been expected by either the proponents or the opponents of single-sex schooling.

Of course, our results relate to schooling in a particular historical period in Britain, and clearly both co-educational and single-sex schools have changed since the 1970s. Equally, both co-educational and single-sex schools differ in different national contexts. One major change in Britain is that many single-sex schools now have mixed "Sixth forms" (the non-compulsory final two years of schooling, from 16 to 18). This allows pupils to mix with the opposite sex before leaving school, and may make future relationship difficulties less likely.

What implications does our study have for today's debates? The fact that girls fared better academically in single-sex than in co-educational schools during the 1970s cannot be taken to imply that this must still be the case. The British birth cohort surveys of 1946,1958 and 1970 have documented the changing relative educational achievements of males and females, alongside changes in the role of women within the labor market and the wider society (Makepeace, Joshi, Woods, \& Galinda-Rueda, 2003). It is not widely recognized that, in terms of overall educational qualifications at 16 , girls were fractionally ahead of boys even in 1974 , when the 1958 cohort were 16 . This is despite the fact that many of the parents and teachers of that generation would not have thought that academic qualifications were as important for girls as they were for boys. Girls' achievement at 16 was in spite of their subordinate status, and boys still achieved higher levels of post-compulsory qualifications. Girls' marginal average advantage at the 5+ A-C benchmark was entirely driven by girls in girls' schools, as co-educated girls were slightly less likely to achieve this benchmark than co-educated boys.

The fact that girls are now outperforming boys in terms of academic attainment at school has been an enormous political issue in countries including Great Britain, the U.S. and 
Australia. It is plausible to infer that, in Britain, this gap would be even larger had it not been for the decline in single-sex schooling. Yet it is important to point out that, if we can extrapolate from our findings, an increase in the provision of single-sex schooling would have improved girls' academic attainments, but not at the expense of the boys, as boys in boys' schools did just as well as co-educated boys.

Hubbard and Datnow (2002) point out that single-sex schooling needs to be driven by an agenda of gender equity for both boys and girls. Of course, we can say the same for coeducational schooling. Our findings have implications for co-educational as well as singlesex schools. In both of these contexts, there is a need to move beyond seeing girls' versus boys' achievement as a zero sum game, where female success must imply male failure. Broader gender issues should not be forgotten: notably, the issue of the ways in which both girls and boys may be trammeled by sex-stereotypes during their school years, which set them on divergent pathways in their later lives and careers. The fact that coeducation has exacerbated the gendered nature of students' attainments, not just at school, but also in terms of their post-school qualifications, suggests that gendered norms regarding education are not immutable, and can be influenced by the context of schooling. The fact that boys and girls still tend to pursue highly gendered educational trajectories suggests that more needs to be done within coeducational schools to challenge this.

From a policy perspective, social impacts need to be considered alongside the academic and economic outcomes. Our work suggests that girls who had attended single-sex schools fared well in examinations at age 16 compared to girls who had attended co-educational schools, and that girls who had attended girls' schools also went on to earn higher wages later in life. Also, self-concept and participation in math and science, English and modern languages, were more starkly gendered for boys and girls in the co-educational schools. Clearly, single-sex schooling had advantages for this cohort, especially for the girls. The difficulty is to weigh 
these advantages against the social disadvantages, which are more apparent for boys than for girls, including a dislike of school and a raised risk of divorce. For a previous generation of "progressive" educationalists, the answer to this dilemma was clear — boys' wellbeing trumped girls' academic attainment. However, these social disadvantages may not be an inevitable consequence of single-sex schooling. No doubt social outcomes varied by individual school, and it is unfortunate that our data do not allow us to investigate such variability. We are also conscious that our findings raise many questions regarding the daily lived experiences underpinning the aggregate differences that we observe here. We hope that future research will be able to take up the issues raised by our findings, and develop them bringing in both quantitative and qualitative longitudinal school and pupil level data. 


\section{References}

Benn, C., \& Simon, B. (1970). Half Way There: Report on the British Comprehensive School Reform. London: Penguin.

Bone, A. (1983). Girls and girl-only schools: a review of the evidence. Manchester: Equal Opportunities Commission.

Brice, I. (1980). The early coeducation movement in English secondary education. Melbourne Studies in Education, 134-177.

Bynner, J., \& Joshi, H. (2007). Building the evidence base from longitudinal data: the aims, content and achievements of the British Birth Cohort Studies. Innovations, 20(2), 159-179.

Dale, A., \& Egerton, M. (1997). Highly educated women: Evidence from the national child development study. London: HMSO.

Dale, R. (1969). Mixed or Single-sex School? Volume I. London: Routledge and Kegan Paul.

Dale, R. (1971). Mixed or Single-sex School? Volume II. London: Routledge and Kegan Paul.

Dale, R. (1974). Mixed or Single-sex School? Volume III. London: Routledge and Kegan Paul.

Dyhouse, C. (1985). Feminism and the debate over coeducational/single-sex schooling: some historical perspectives. In J. Purvis (Ed.), The education of girls and women. Leicester: History of education society.

Faraday, A. (1989). Lessoning lesbians: girls' schools, co-education and anti-lesbianism between the wars. In C. J. a. P. Mahony (Ed.), Learning our lines. London: The women's press.

Goldthorpe, J., \& McKnight, A. (2006). The economic basis of social class. In S. Morgan, D. B. Grusky \& G. S. Fields (Eds.), Mobility and Inequality: Frontiers of research from sociology and economics. Stanford: Stanford University Press. 
Hakim, C. (1998). Social change and innovation in the labour market. Oxford: Oxford University Press.

Hawkes, D., \& Plewis, I. (2006). Modelling Non-Response in the National Child Development Study. Journal of the Royal Statistical Society, A., 169, 479-491.

Hubbard, L., \& Datnow, A. (2002). Are Single-sex Schools Sustainble in the Public Sector. In A.

Datnow \& L. Hubbard (Eds.), Gender in Policy and Practice: Perspectives on single-sex and co-educational schooling (pp. 109-132). New York: Routledge Falmer.

Leonard, D. (1996). The debate around coeducation. In S. Kemal, D. Leonard, M. Pringle \& S. Sadeque (Eds.), Targeting Underachievement: boys or girls? London: Institute of Education.

Leonard, D., Joshi, H., \& Sullivan, A. (2007). Single-sex and co-educational schooling: Lifecourse consequences? : ESRC report.

Makepeace, G., Joshi, H., Woods, L., \& Galinda-Rueda, F. (2003). From School to the Labour Market. In E. Ferri, J. Bynner \& M. Wadsworth (Eds.), Changing Britain Changing Lives. London: Bedford Way Papers.

Power, C., \& Elliott, J. (2006). Cohort profile: 1958 British Birth Cohort (National Child Development Study). International Journal of Epidemiology, 35(1), 34-41.

Rutter, M., Tizard, J., \& Whitmore, K. (1970). Education, Health and Behaviour. London: Longmans.

Shaw, J. (1976). Finishing School: some implications of sex-segregated education. In D. L. Barker \& S. Allen (Eds.), Sexual Divisions and Society: process and change. London: Tavistock.

Smithers, A., \& Robinson, P. (2006). The Paradox of Single-sex and Co-educational Schooling: University of Buckingham.

Spender, D., \& Sarah, E. (Eds.). (1980). Learning to Lose: sexism and education. London: Women's Press. Spielhofer, T., Benton, T., \& Schagen, S. (2004). A study of the effects of school size and single-sex education in English schools. Research Papers in Education, 19(2), 133-159.

Steedman, J. (1980). Progress in Secondary Schools. London: National Children's Bureau. 
Steedman, J. (1983a). Examination Results in Mixed and Single Sex Schools: Findings from the National Child Development Study. Manchester: Equal Opportunities Commission.

Steedman, J. (1983b). Examination Results in Selective and Non-Selective Schools. London: National Children's Bureau.

Steedman, J. (1983c). Examination Results in Selective and Non-selective Schools, Volume 2 - Appendices. London: National Children's Bureau.

Sullivan, A. (2006). Academic self-concept, Gender and Single-sex Schooling in the 1970 Cohort. CLS Working Paper, London: Centre for Longitudinal Studies, 2006(2).

Sullivan, A. (2009). Academic self-concept, gender, and single-sex schooling. British Educational Research Journal, 35(2), 259-288.

Sullivan, A., Joshi, H., \& Leonard, D. (2010). Single-sex Schooling and Academic Attainment at School and through the Lifecourse. American Educational Research Journal, 47(1), 6-36.

Sullivan, A., Joshi, H., \& Leonard, D. (2011). Single-sex schooling and labour market outcomes. Oxford Review of Education, 37(3), 311-332.

Sullivan, A., Joshi, H., \& Leonard, D. (2012). Single-sex and co-educational schooling: What are the social and family outcomes, in the short and longer term? Longitudinal and Life Course Studies, 3(1), $137-157$.

Warrington, M., \& Younger, M. (2001). Single-sex classes and equal opportunities for girls and boys: perspectives through time from a mixed comprehensive school in England. Oxford Review of Education, 27(3), 339-356.

Younger, M., \& Warrington, M. (2006). Would Harry and Hermione have done Better in Single-Sex Classes: A review of single-sex teaching in co-educational schools in the United Kingdom. American Educational Research Journal, 43(4), 579-620. 
Table 16.1: Attendance at a single-sex school, contrasted with attendance at a mixed school, binary logistic regression

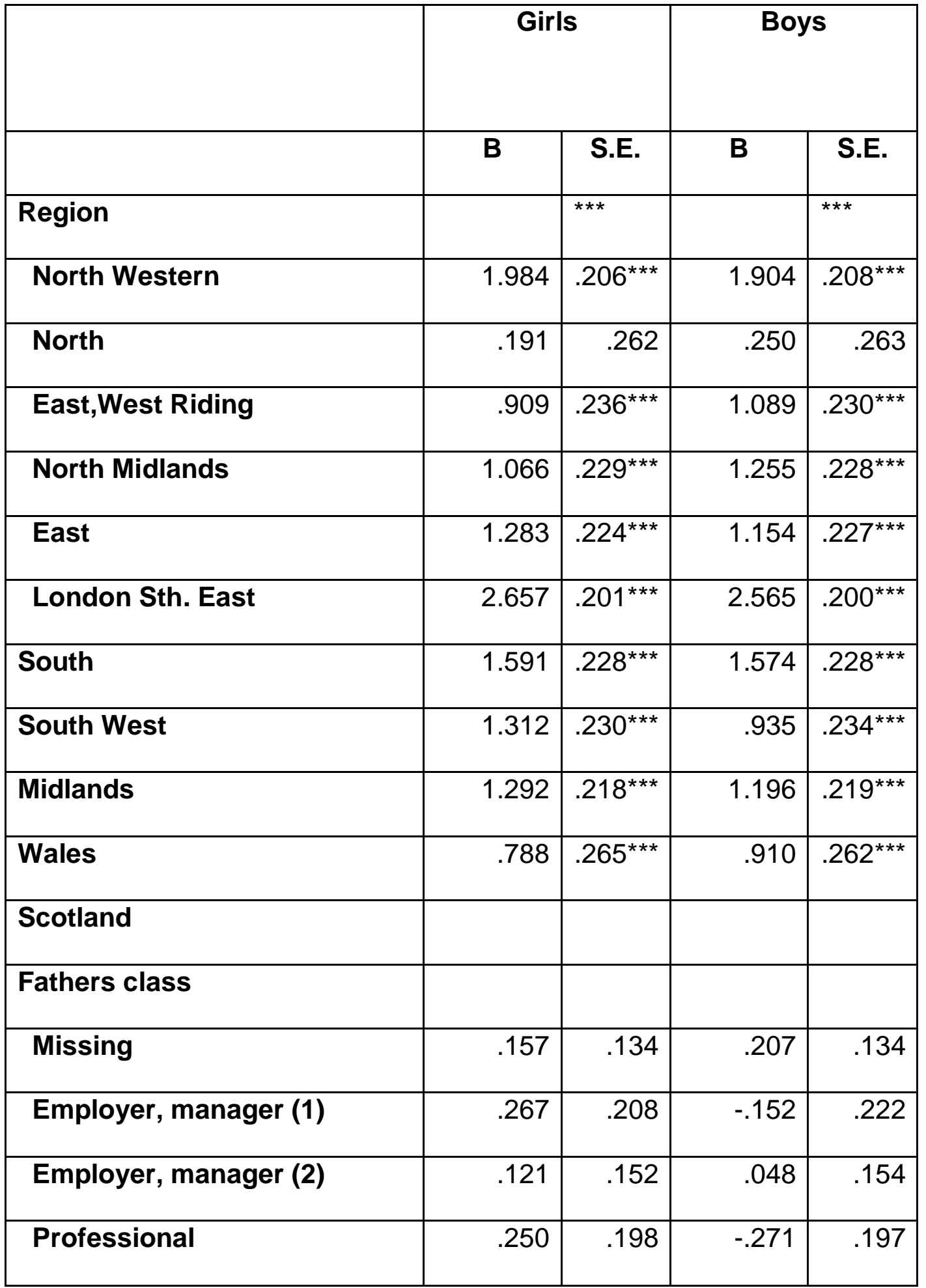




\begin{tabular}{|c|c|c|c|c|}
\hline Own account & .166 & .206 & .048 & .203 \\
\hline Non-manual & .282 & $.141^{*}$ & -.003 & 146 \\
\hline Skilled manual & .101 & .115 & .055 & .117 \\
\hline \multicolumn{5}{|l|}{ Unskilled manual } \\
\hline Parents' education & & ** & & ** \\
\hline Missing & .354 & $.101^{\star \star \star}$ & 320 & $.103^{* *}$ \\
\hline $19+$ & .198 & .146 & .111 & .152 \\
\hline 17-18 & -.042 & .116 & -.073 & .119 \\
\hline 16 & .052 & .104 & .000 & .107 \\
\hline \multicolumn{5}{|l|}{ Left school pre 16} \\
\hline Cognitive test score age 11 & .004 & .003 & .004 & $.003^{*}$ \\
\hline Secondary school sector & & 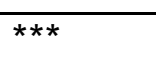 & & $\star \star \star *$ \\
\hline Private & 2.002 & $.608^{\star \star \star}$ & .986 & .505 \\
\hline Grammar & 1.564 & $.500^{* *}$ & 3.092 & $.517^{\star \star \star}$ \\
\hline Secondary Modern & 1.116 & $.256^{\star \star \star}$ & .811 & $.247^{\star \star \star}$ \\
\hline \multicolumn{5}{|l|}{ Comprehensive } \\
\hline Test Score*School & & ** & & 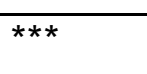 \\
\hline Test score ${ }^{\star}$ Private & .025 & $.010^{*}$ & .037 & $.009^{\star \star \star}$ \\
\hline Test score ${ }^{\star}$ Grammar & .014 & .008 & -.005 & .008 \\
\hline Test Score ${ }^{\star}$ Secondary Modern & -.009 & .006 & .000 & .005 \\
\hline Constant & -3.685 & .282 & -4.064 & .279 \\
\hline $\mathbf{N}$ & 6052 & & 6263 & \\
\hline Chi-Square & 2035.487 & $\star \star * \star$ & 1924.798 & *** \\
\hline
\end{tabular}

Note: 371 students at special schools and schools outside standard categories excluded 
Figure 16.1: Pupils' responses to 'I do not like school', at age 16 (1974)

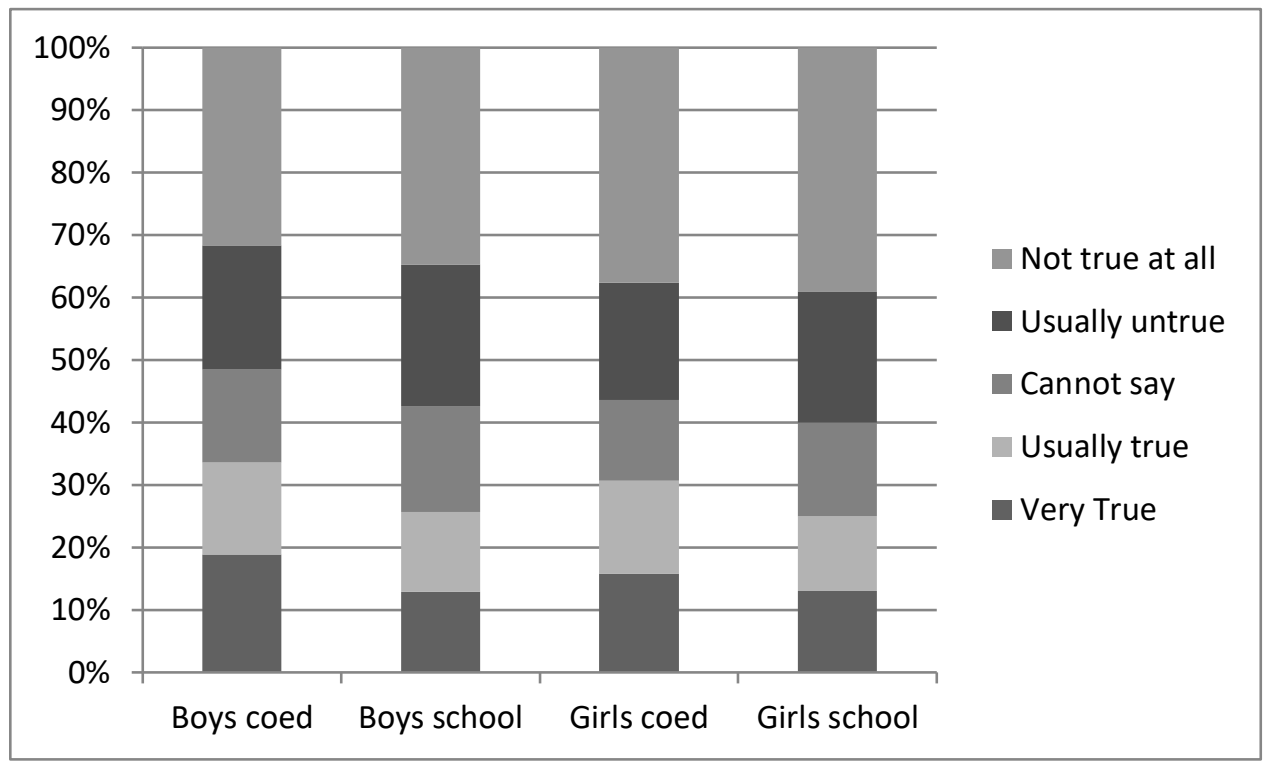

$\mathrm{N}=11,688$

Figure 16.2: Percentage liking school at age 16 by type of school

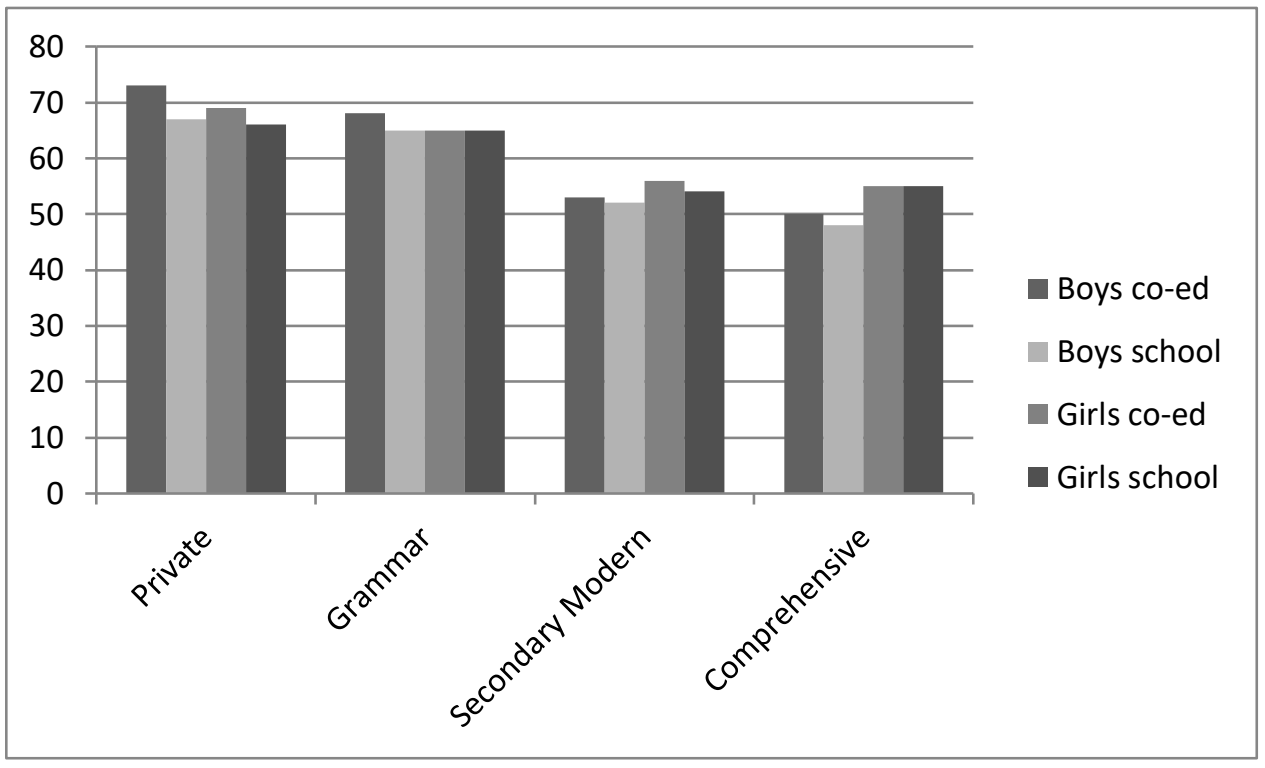

$\mathrm{N}=11,688$ 
Figure 16.3: Self-concept in maths, English and science

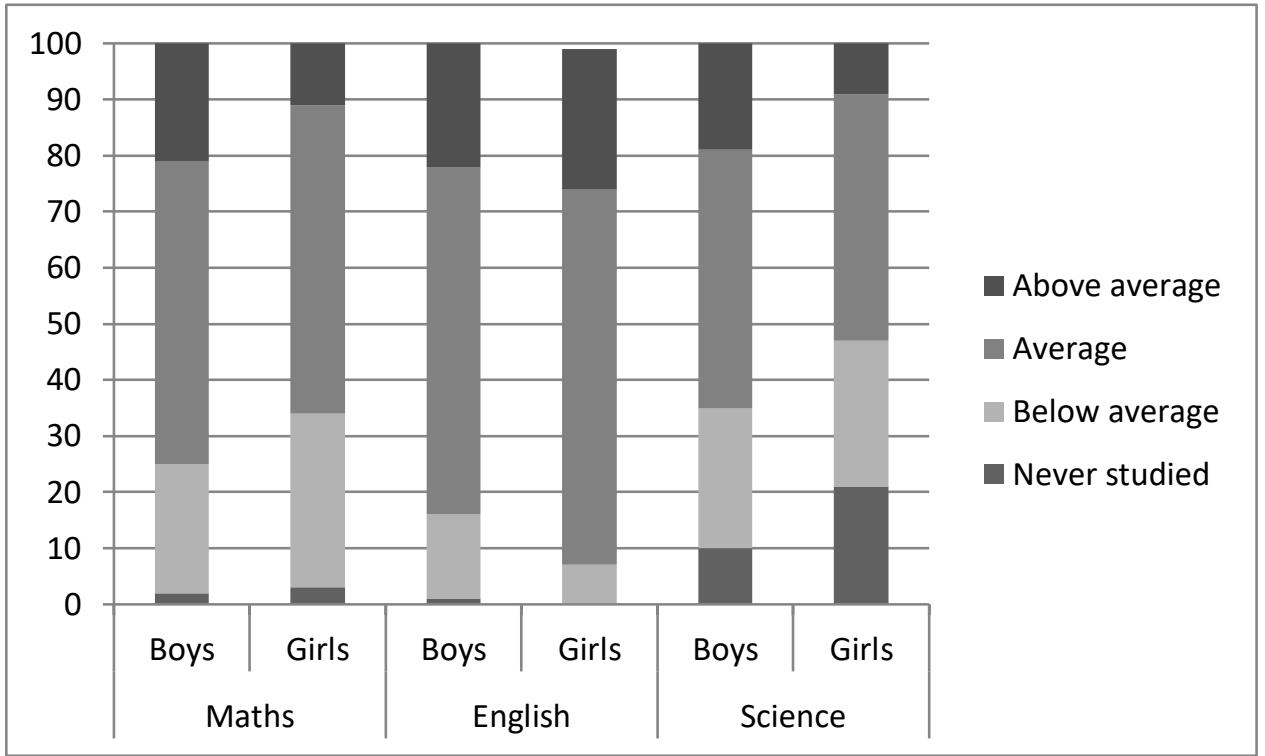

Figure 16.4: 5 or more O-level passes 


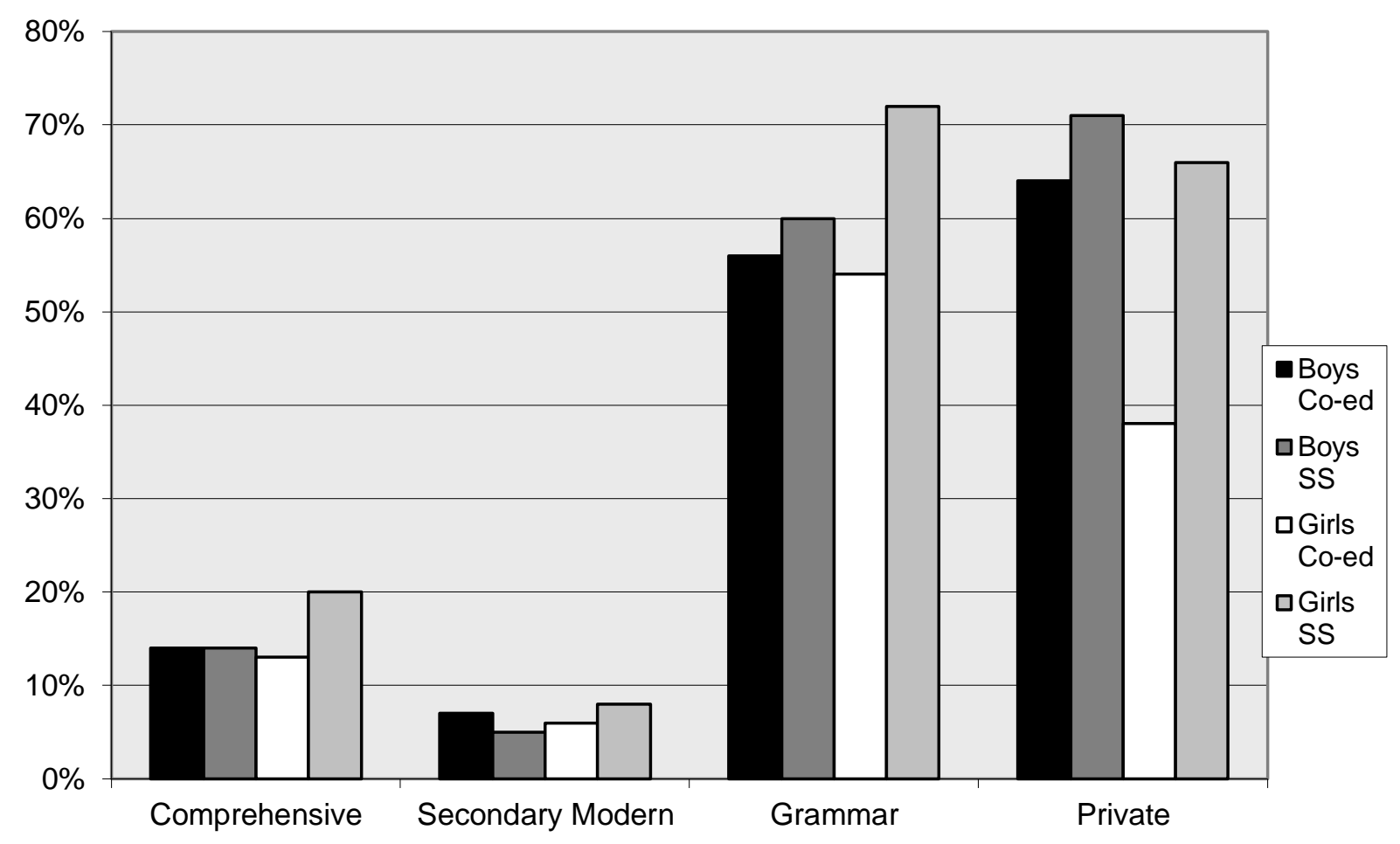

Figure 16.5: O-level Subject passes 


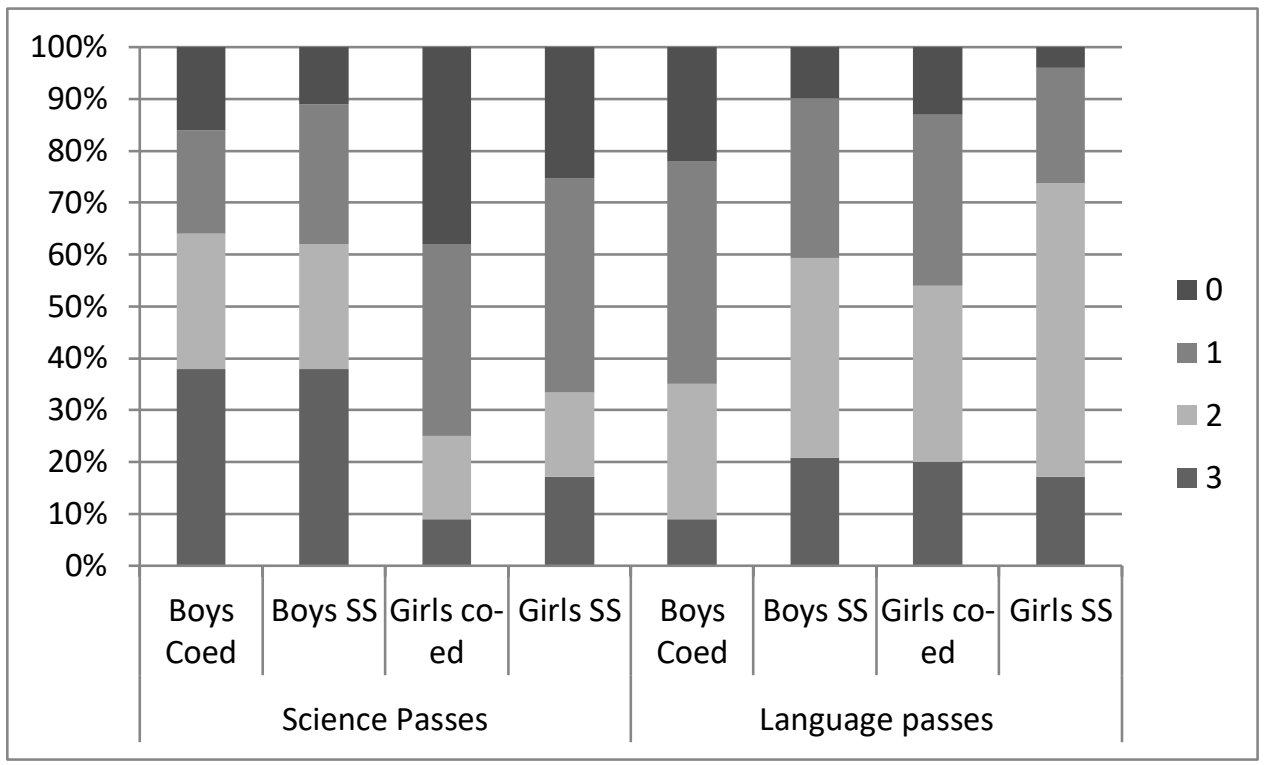

*Cohort members with at least one pass in any subject. "Science" = physics, chemistry, math.

"Languages"= English, French, another modern language.

Figure 16.6: A-level subject passes

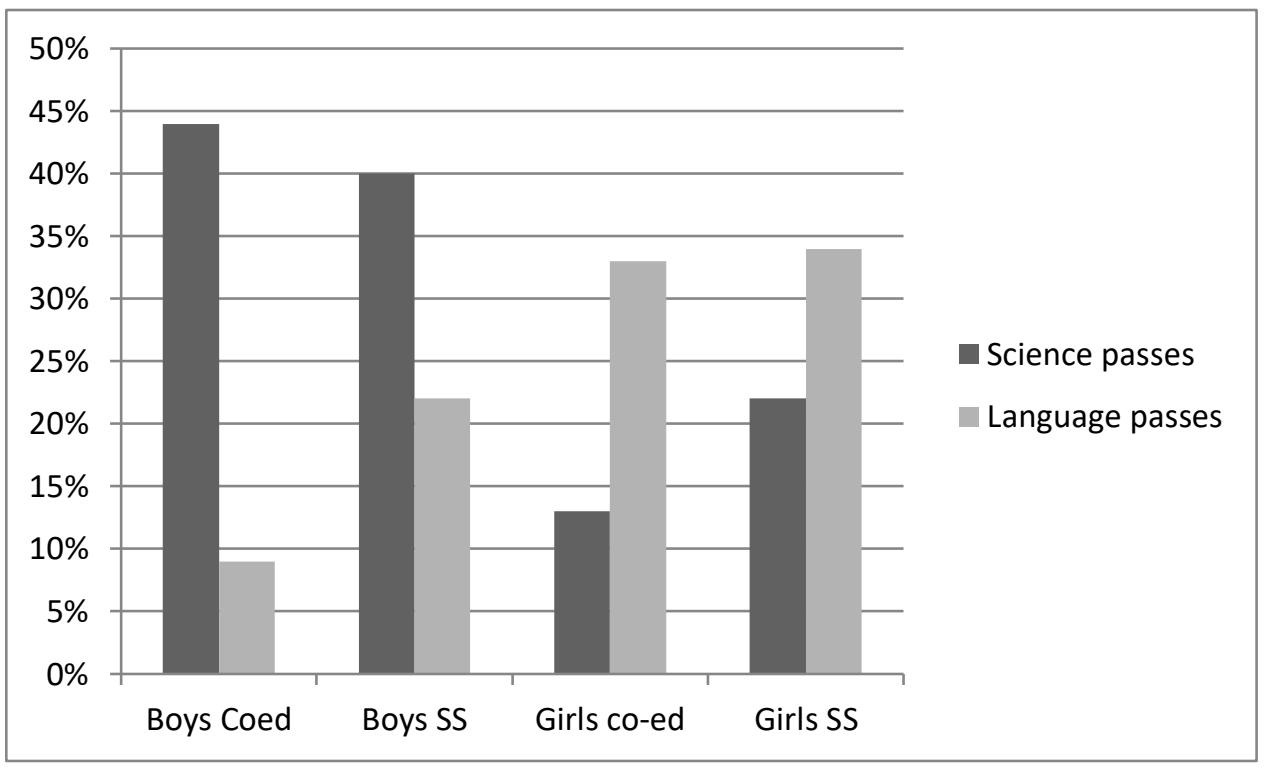


*Includes only pupils who achieved at least one A-level pass.

Figure 16.7: Sex composition of highest qualification age 33

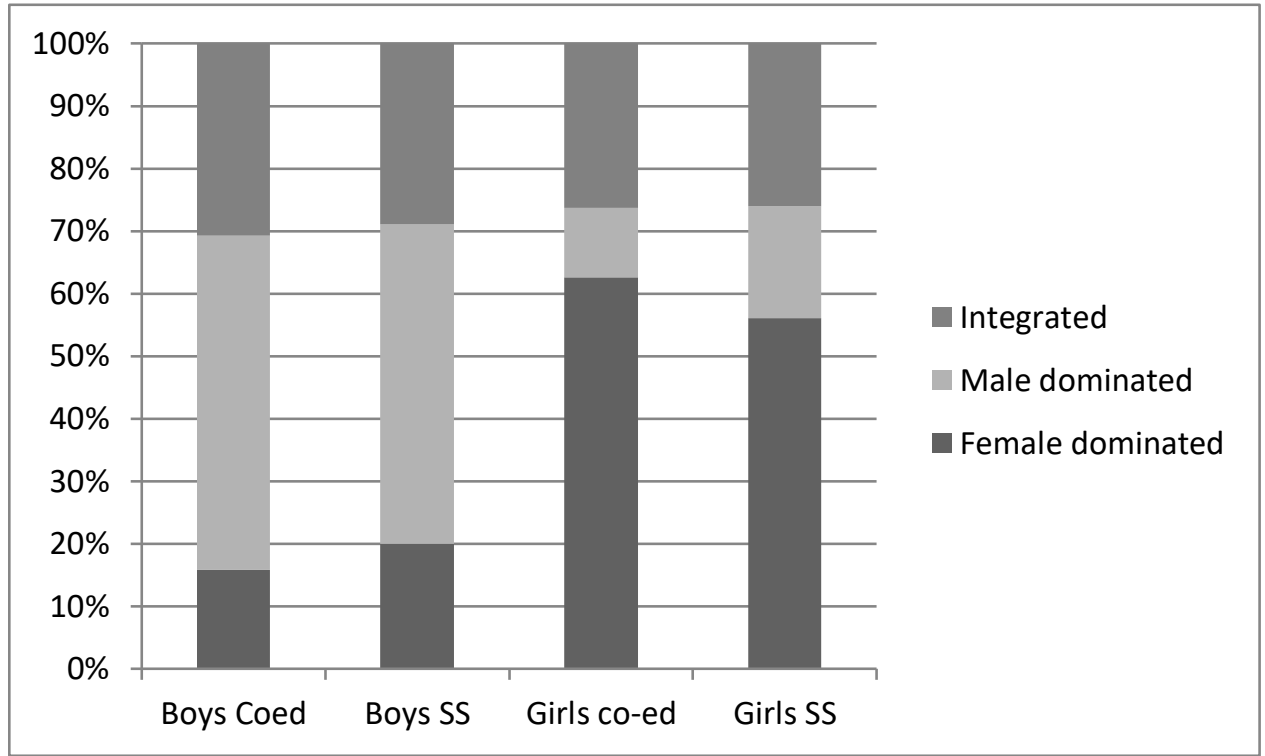

Figure 16.8: Divorce or separation by age 42 , by gender and school sector 


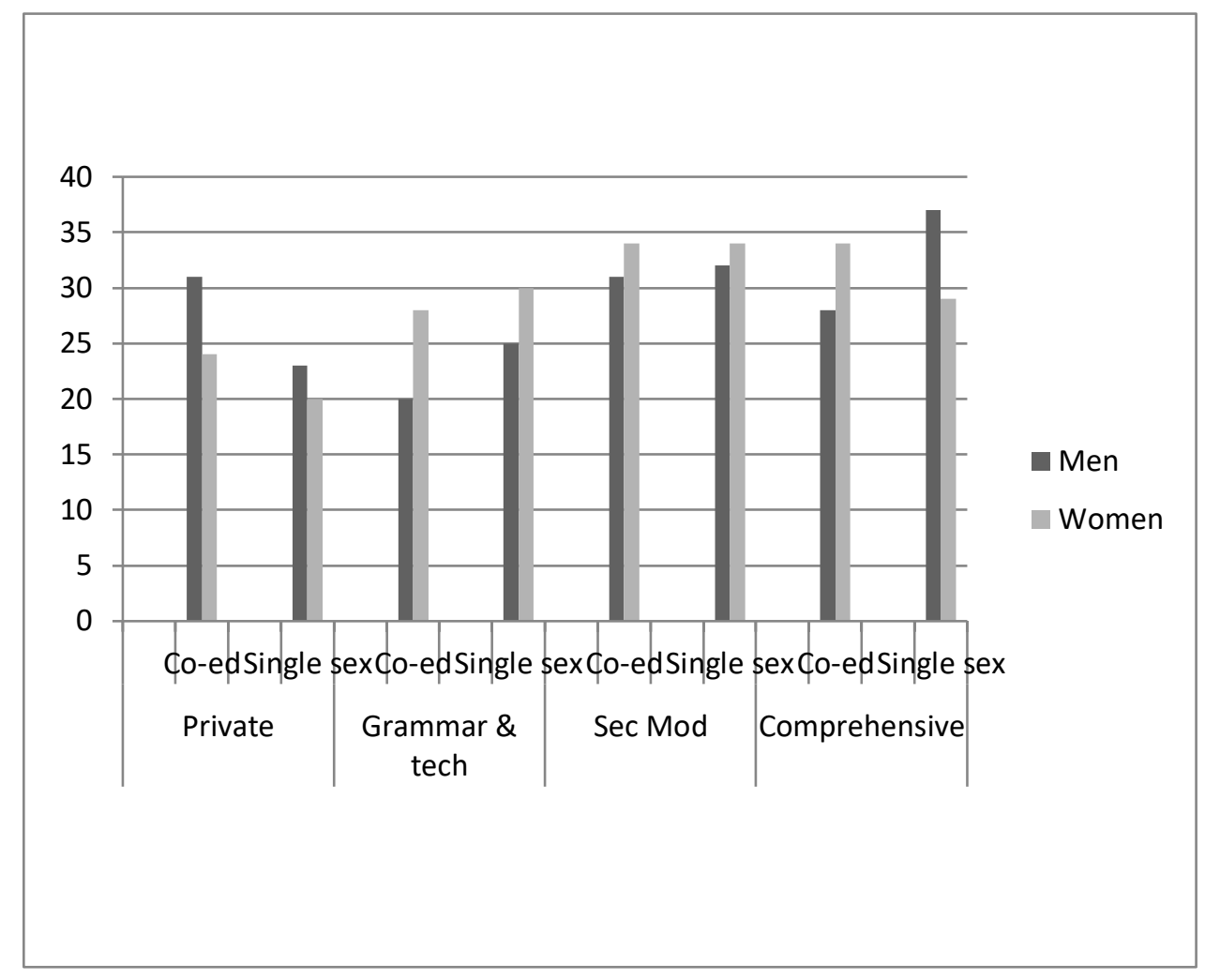

Table 16.2: Economic activity at 42 , by gender

\begin{tabular}{|l|c|c|c|}
\hline Main economic activity & Men & Women & Total \\
\hline Full time employment & $\%$ & $\%$ & N \\
\hline Part time employment & 2 & 34 & 2107 \\
\hline Family & 1 & 13 & 791 \\
\hline Unemployed including govt. & 3 & 2 & 269 \\
scheme & & & \\
\hline F.T. education & 0.2 & 1 & 58 \\
\hline
\end{tabular}




\begin{tabular}{|l|c|c|c|}
\hline Disabled or sick & 5 & 5 & 533 \\
\hline Retired or other & 1 & 1 & 108 \\
\hline TOTAL N & 5608 & 5772 & 11380 \\
\hline
\end{tabular}

Figure 16.9: Socio-economic class of cohort member at current or most recent job by age 42 by gender

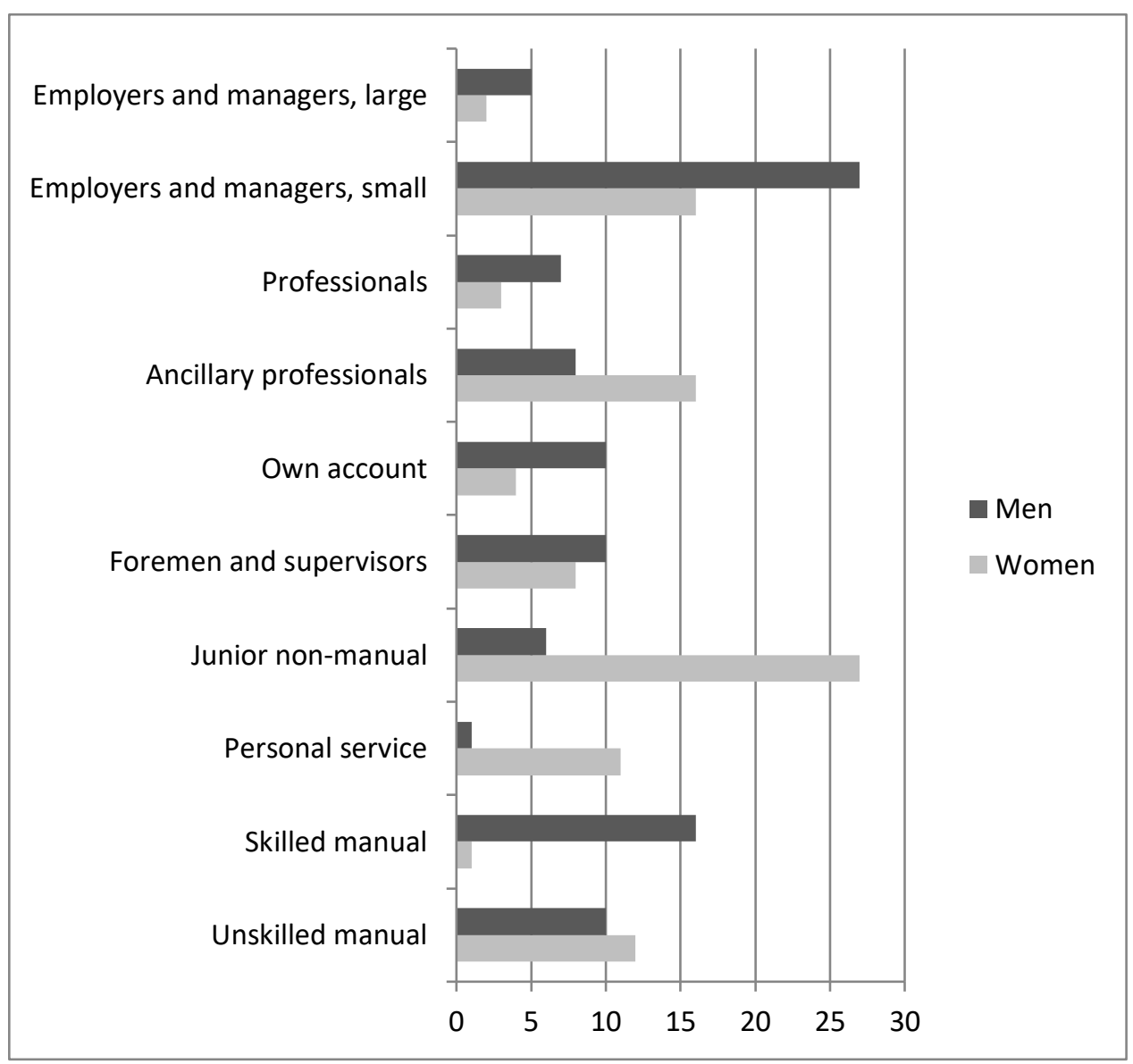


Figure 16.10: Occupational segregation (Hakim's classification) at current or most recent job by age $42 *$

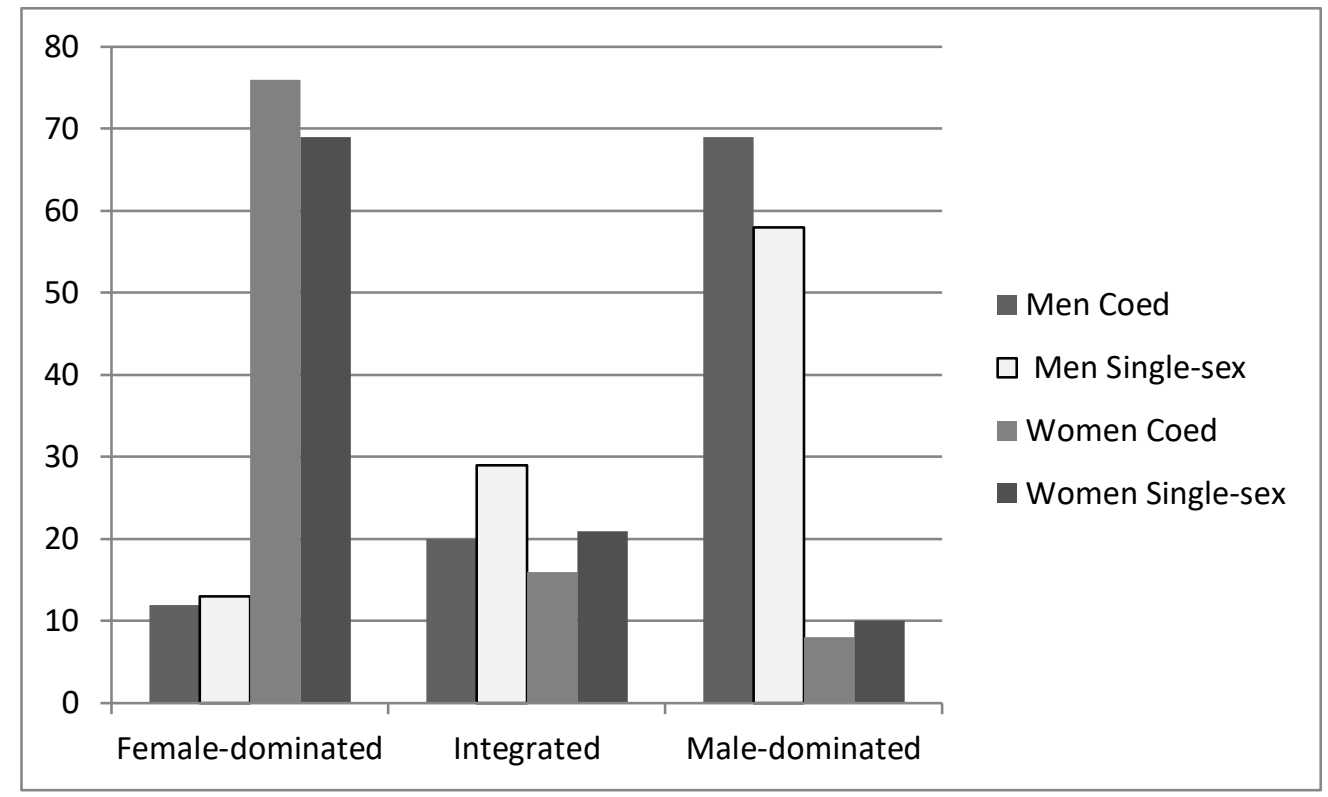

* Includes only those currently employed at age 42

Figure 16.11: Hourly wages (f) of those employed at 42 


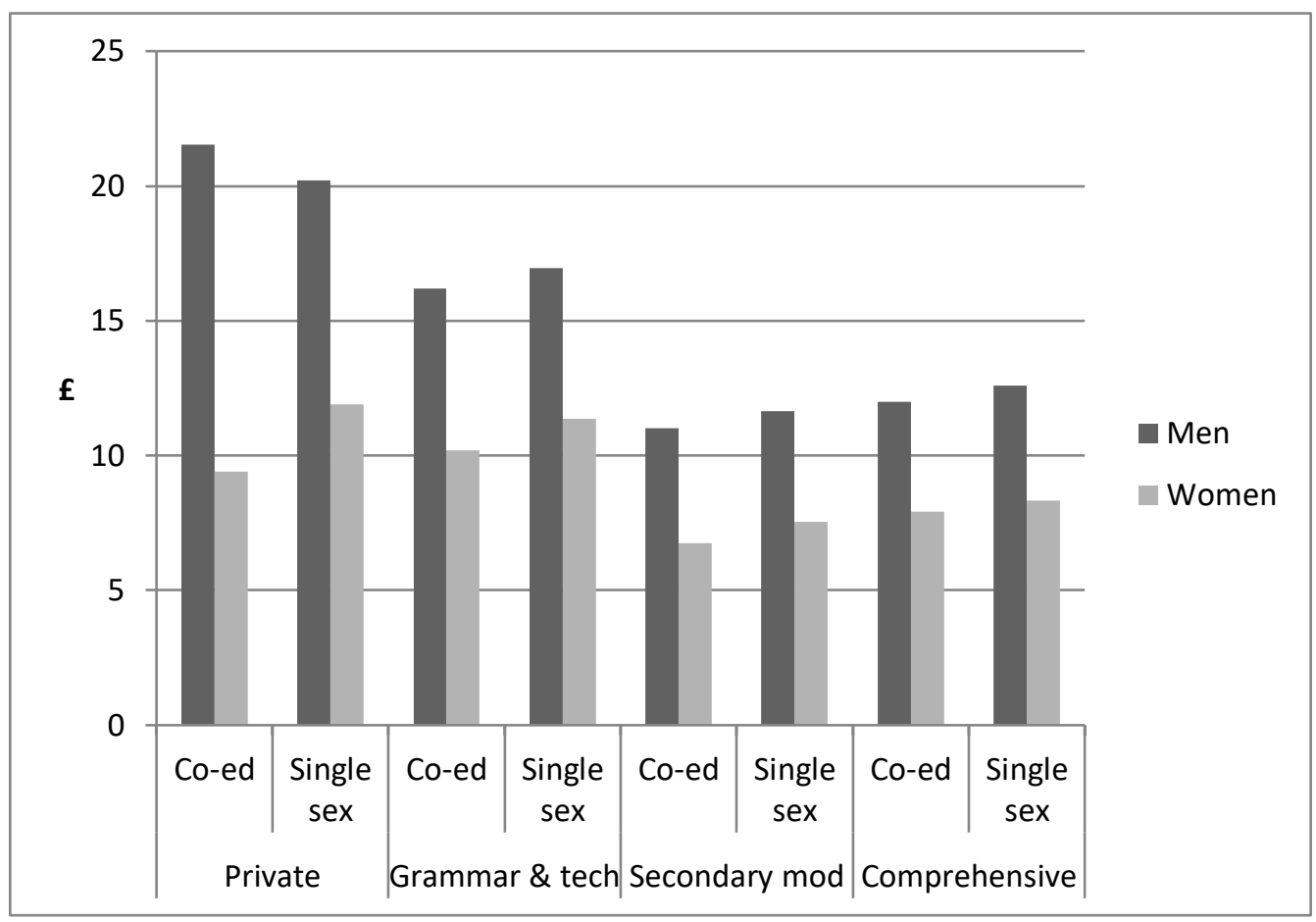

